\title{
Impact of COVID-19 Pandemic on Ordinary People; A Social Distancing Challenge
}

\author{
Fahim Aslam ${ }^{1}$ \\ University of Bedfordshire \\ fahimaslam30@gmail.com
}

\begin{abstract}
COVID-19 has become a part of everyone's day-to-day life, since the outbreak in 2019 the novel coronavirus disease (COVID-19) has caused more than 4.5 million deaths with over 200 million cases reported globally. Currently, the number of infections and deaths are gradually lowering in different countries however the underlying challenges still exist. COVID-19 threatens human life, social functioning and development. Although numerous studies have been carried out in the past to highlight the key challenges very limited studies have been conducted from an ordinary person's viewpoint. In the fight against COVID-19, humanity has been pushed to a level which cannot be accepted where establishing that balance is a priority. This study focuses on highlighting the common issues faced by the ordinary public in the current era. Five key areas were identified to be the most essential: education, technological adaptation, transportation, mental health and gender-based violence (GBV).
\end{abstract}

Keywords: COVID-19, Pandemic, Social Challenge, GBV, Healthcare Management, Health Policy 


\section{Introduction}

Since the outbreak of COVID-19 in 2019 more than 4.5 million people have died and over 200 million cases have been reported in the past 18 months. As highlighted by [1] the impact of the virus has resulted in several countries implementing strict laws and regulations with social distancing measures to combat the virus spread. As per Figure 1, America, India and Brazil are the most affected countries with a cumulative case count more than 100 million and nearly 1.5 million deaths.

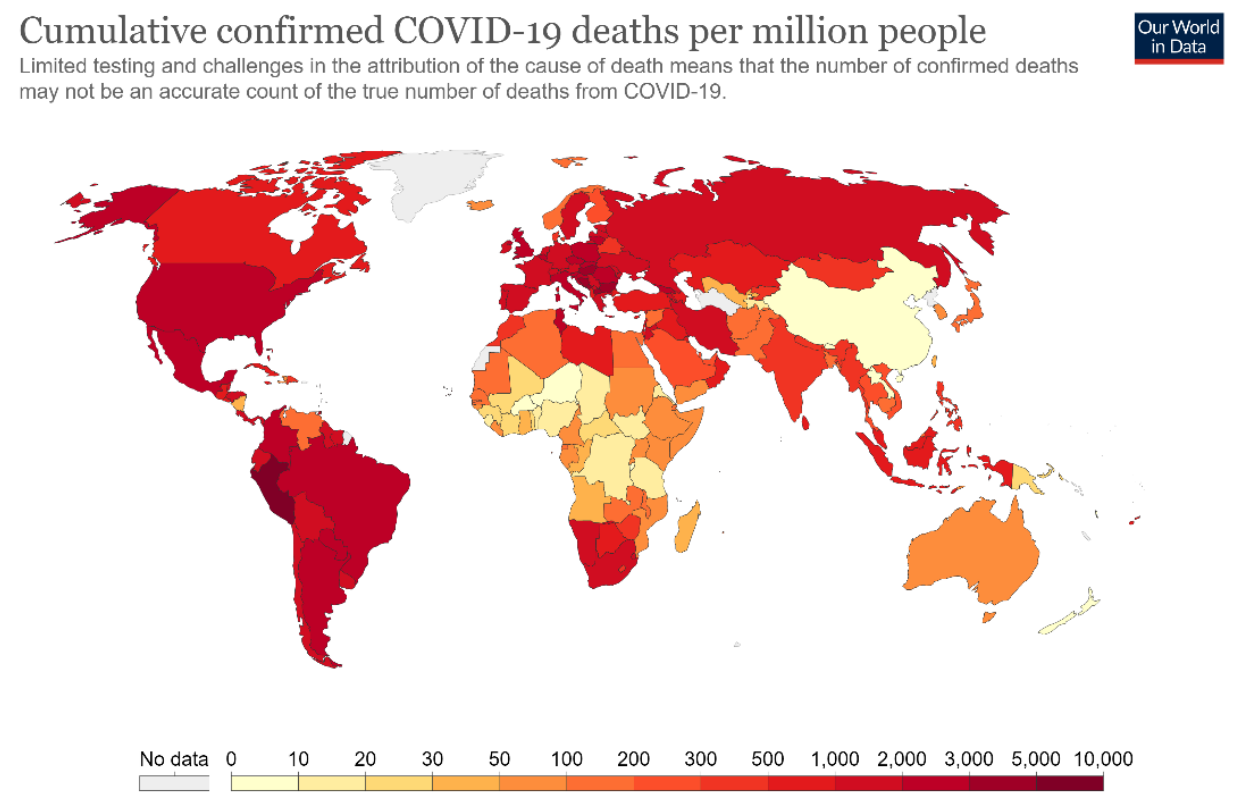

Figure 1: Cumulative Case Count Globally

With the availability of vaccines and donations being made by various international organizations several countries have been able to vaccinate the vast majority [2]. As indicated in Figure 2 countries across Asia and Europe have been rolling out vaccines at a rapid phase to prevent any future outbreak, however with increase vaccination rollout the number of testing has also reduced significantly which is a warning for countries as there is a possibility of a new variant emerging due to this [3]. The biggest threat faced by low-middle income countries is the lack of investment made towards procuring the vaccines which can result in more muted variants being developed [4]. Currently over 15 different variants are being monitored with 6 high threat variants identified as per WHO [5] tracking system. 
Daily new confirmed COVID-19 deaths per million people

Shown is the rolling 7-day average. Limited testing and challenges in the attribution of the cause of death means that the number of confirmed deaths may not be an accurate count of the true number of deaths from COVID-19.
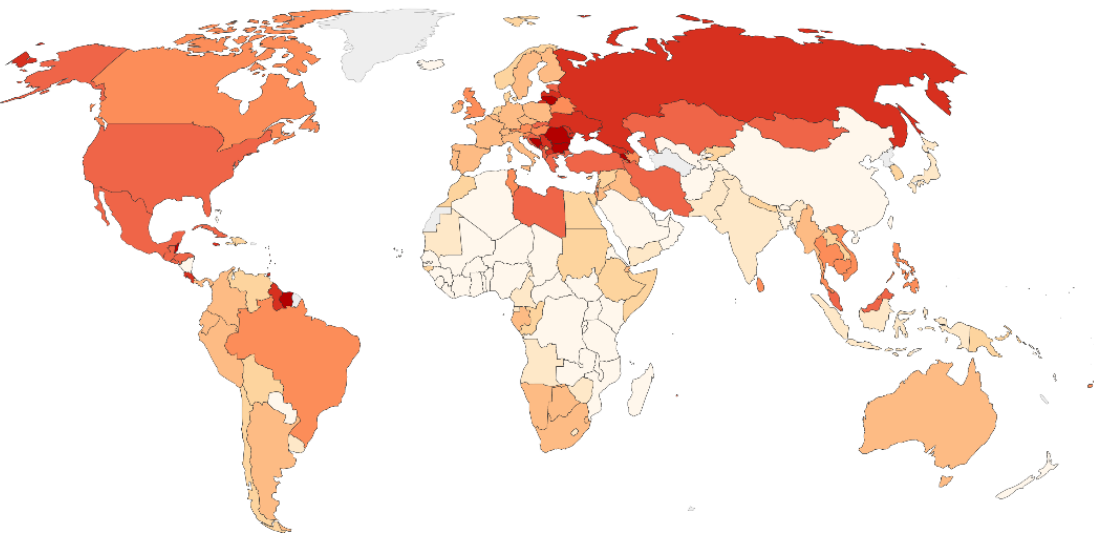

No data 0 $0.1 \quad 0.2$ 0.5 12 5 1020

Figure 2: Latest COVID-19 heatmap

Daily new COVID-19 tests per 1,000 people Shown is the rolling 7-day average.
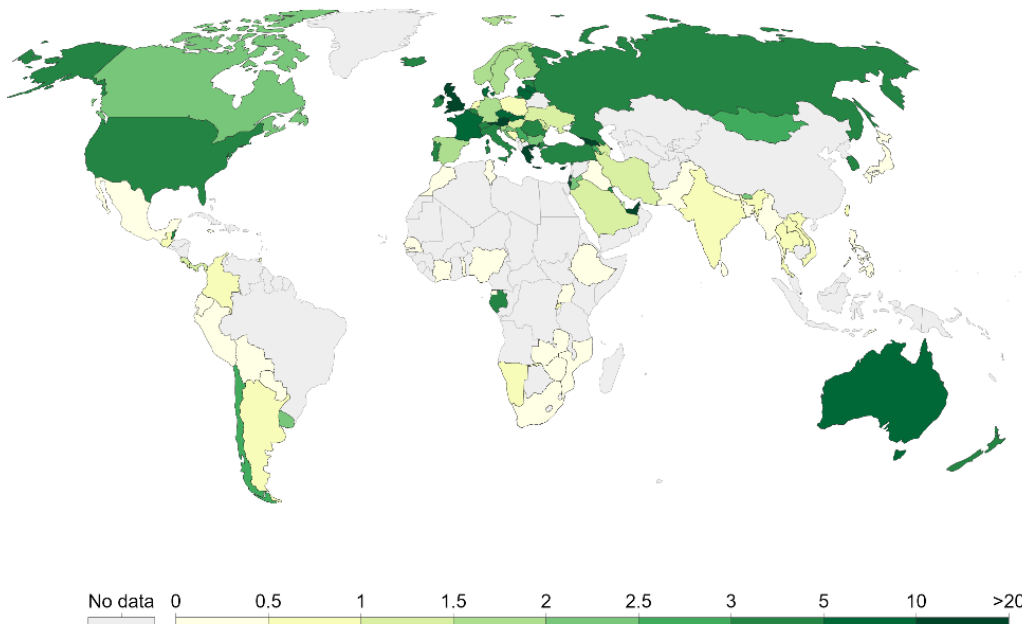

Figure 3: COVID-19 testing rate

Even with the intensified tracking, online surveillance, testing, and vaccination programs being rolled out globally the factor or thought of "returning back to normal" is still a concern among the general public. This paper plans on highlighting the key challenges and possible mitigation strategies that can be adapted to reduce the risk of COVID-19 spread. 


\section{Challenges to the New Normal}

\section{Public Transportation}

According to the latest land transport statistics, there is a decline of $37 \%$ using public transportation post the pandemic [6]. Although these figures can change significantly in different countries there is a clear indication that public are remaining cautious over the COVID-19 spread and trying to protect themselves from the virus outbreak. Globally only 56 countries have access to high-speed metros while the remaining countries rely heavily on trains and buses as the main mode of transportation specially in the low-and middle-income countries [7].

One of the common features of the public transportation system in recent times have been the inclusion of a sanitation bottle at the entrance to ensure passengers clean themselves before entering the bus. Additionally, passengers are requested to wear the face masks at all times to reduce the risk of virus spread, however there a few drawbacks as well where social distancing is not practiced in most instances and there are high chances of the virus remaining inside the transportation vehicle as they are not sanitized after the passengers have left [8].

With majority of the population relying on public transportation for travel purposes there is a significantly high risk imposed to the public as COVID-19 has changed people's day-to-day habits. As stated by Balanzá [9] protective measures with limited risks needs to be adapted to ensure that individuals using public transport for travelling are protected from the COVID-19 virus as patients can be carriers of the virus and remain asymptomatic.

Another drawback or challenge identified by the public is the common of sitting next to each other, although social distancing rules have been imposed not every passenger or transport service will be using it to full effect as the economic outlook overshadows the health perspective. Health and healthcare systems interrelate with the economy as several developing countries focus on improving the healthcare and educational system in the country which will be improve the standards of living in the country. Post the pandemic a significant budget has been allocated towards health and research related interventions to prevent another possible outbreak of COVID-19. However, as stated by McKee [11] economic stability is also essential to continue to improve these systems which makes public transport a key area of income for the country to invest towards [12]. 


\section{Technological Adaptations}

Within the first few months of COVID-19 being declared as a pandemic all sectors across the world had to follow and abide by the COVID-19 guidelines provided by the health officials. This led to the new concepts of "work from home" and digitalization of work [13].

One of the major highlights during COVID-19 is the "adoption acceleration rate" where employees, customers and business organizations have found ways to use technology to adapt to the changes in working modalities. This has increased avenues for small-scale enterprises and businesses to expand their scope of business using online e-commerce platforms at a relatively low startup cost. Bhatti [14] highlighted that e-commerce platforms such as Amazon, E-bay continued to increase their revenue during the pandemic as majority of the population were shopping from home. Moreover, several essential services adapted to the online trends where patient care, emergency health and government institutional services were provided to the public using technology.

However, this adaption also has its own challenges as the increased number of online interventions could also make it easy for cyber attacks to take place. As indicated by Zwilling [15] over relying on social media platforms and e-commerce networks without taking adequate security measures can result in data loss and chances of being hacked. In recent times platforms such as Facebook, WhatsApp and Instagram have experienced severe blackouts resulting in billions of revenue losses experienced by both business entities and organizations [16]. Sharma [17] in his study identified that "technology driven" solutions has evolved and changed the ways of thinking at both the governance and the administration level globally. Another main issue with technology is that not all working modalities can be adapted to this style of working, companies such as food manufacturers, telecommunications department and physical workforce are required to be present to carry out their work in person. The fashion and garment industry was affected the most as the employees were unable to function as normal which resulted in severe workforce reduction in countries around South Asia [18].

Rural parts of several countries have been severely suffering due to this as most of these regions are in regions with limitations in internet connectivity. This is mainly because majority of the countries focus heavily towards providing urban cities with adequate technology unlike the rural parts of the country [20]. With all these challenges imposed, a strategic framework is required by both the government and the network providers to find alternative solutions to mitigate these risks. 


\section{Online Education}

As highlighted by UNICEF, nearly 463 million children globally have no access to remote learning while 3 out of 4 students cannot be reached by remote learning opportunities come from rural areas and/or poor households. Although business and small-scale enterprises have been using technology in terms of education there has been a significant drawback. As indicated in below Figure 4 majority of the households are relying heavily on television for online learning which highlights the technological divide in education.



Sources: UNESCO-UNICEF-World Bank Survey on National Education Responses to COVID-19 School Closures (2020) and UNICEF country offices (2020). Note: Figures are estimated using simple averages across countries.

Figure 4: Learning policies against education level globally

Figure 5 highlights that only $69 \%$ of the global population have access to technology through remote learning which is an estimate and could be even lower over time. There is a correlation between the level of income and access to technology specially in low- and middle-income countries, as illustrated by Nasution [20] this is a common problem observed since the early 90 's. 


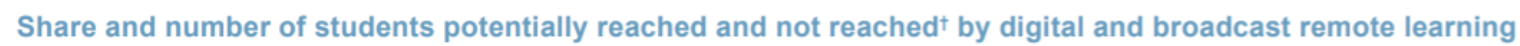
policies, by region (pre-primary to upper secondary)



Figure 5: Remote learning breakdown in different regions

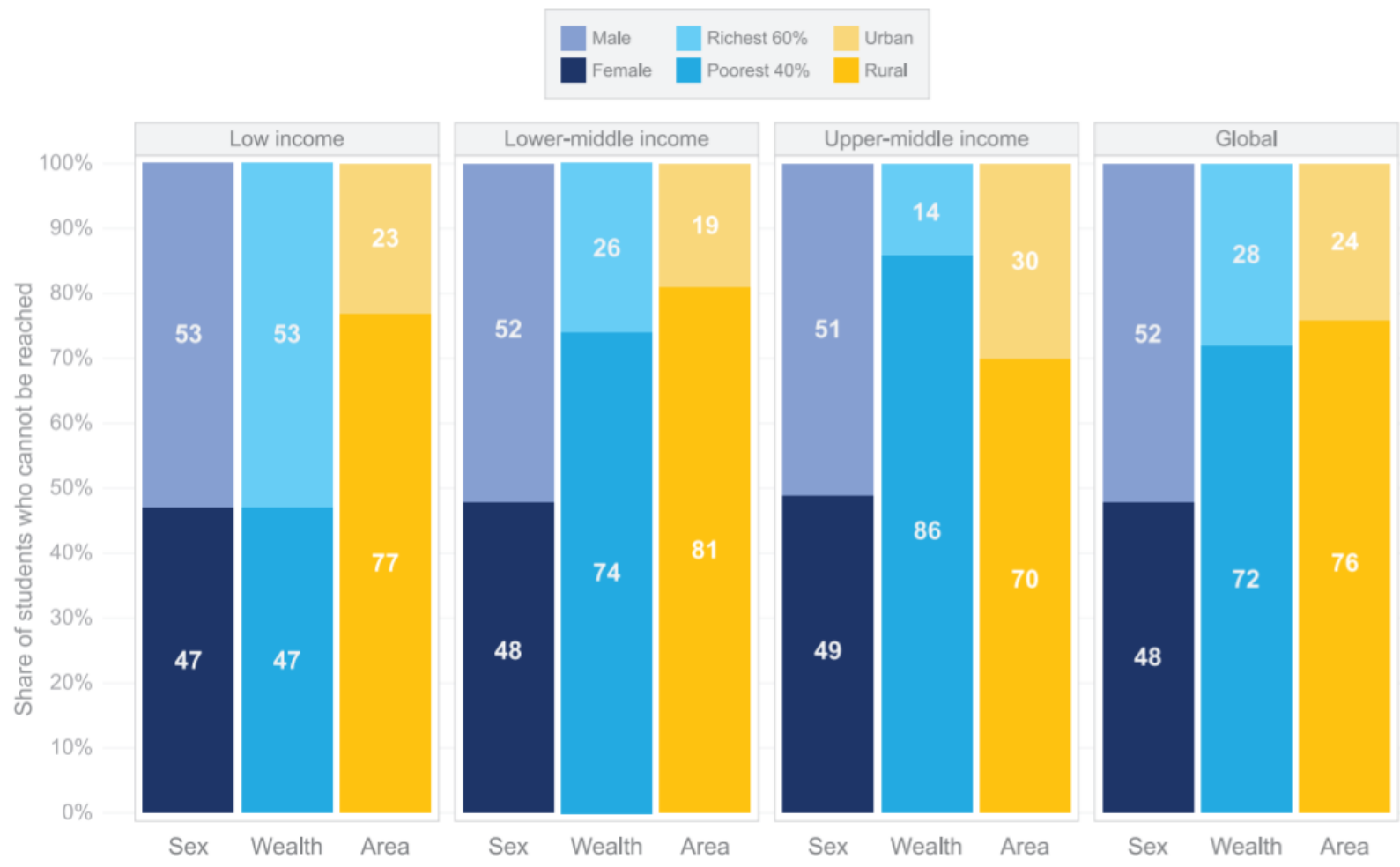

Figure 6: Income Levels in Various Countries 
With the adaptation of online learning, students are not provided with the in-class experience which makes it harder for them to communicate and engage with each other. Parents and teachers also find it difficult to monitor and keep track of each student's movements over the video as everyone is given equal attention unlike in class where you can make observations in person. The classroom atmosphere and environment cannot be established at home since the limitations in different households, even though efforts have been made to create virtual backgrounds and using interactive tools it has never been successful [21].

Cost of internet and limited access to electronic devices is also another factor which impacts online learning. As stated by Singh [22] the rise of IoT applications has been immense transforming lives of the urban population significantly, however this also creates a vacuum among people with limited access to internet connectivity. In Bangladesh students have suffered to a great extend due to the high cost of internet packages and some had no electronic devices at all resulting in limited opportunities to engage in learning during COVID-19 [23]. Despite the world moving at a rapid phase with technology-driven industries on the rise, the educational challenges still exist in most parts of the world indicating a divide between several countries.

\section{Mental Health}

The COVID-19 pandemic and its social and economic impact have induced emotional stress among individuals globally. This can range from health and well-being related complications to excessive substance usage [24] which can create an emotional distress among the public. Although mental health issues are not discussed widely the impact it has created during the pandemic is a growing concern. A study carried out by UNICEF [25] indicated that nearly $42 \%$ of adolescents were either having anxiety or depression because of economic situation imposed by the COVID-19 pandemic. Moreover, nearly 1 in 3 people had reached out to their friends or searched for help during the pandemic as they felt isolated and worried about the future.

The thought of losing a family member, job loss and thoughts about the future does impact the wellbeing of individuals significantly. Signs of insomnia and post traumatic stress disorder were identified as common issues faced by individuals during the pandemic [26] as they were unable to cope with the situational changes around them. Beyond this, the mass home-confinement directives including stay-athome orders, quarantine, and isolation became a burden to individuals at home as they felt trapped from the outer world. 
Adding to these concerns, studies have indicated that social media addiction has been on the rise during the pandemic as the household members run out of things to do at home. Sun [27] illustrated in his study that nearly $46 \%$ of participants indicated that they are increasingly dependent on the internet with nearly $4 \%$ severely addicted as they felt like social media is the only way of escaping and spending time during the pandemic.

People going through these issues begin fearing for their health and their jobs, and are forced to live an unfamiliar lifestyle, deprived of relationships. This situation may have influenced and pushed more people towards a deviant behavior linked to licit or illicit substance use forcing them to leave home during restrictions [28]. All these factors collectively indicate the significance of the pandemic towards the mental health and wellbeing of individuals.

\section{Younger Adults are More Likely to Report Symptoms of Anxiety and/or Depressive Disorder During the COVID-19 Pandemic}

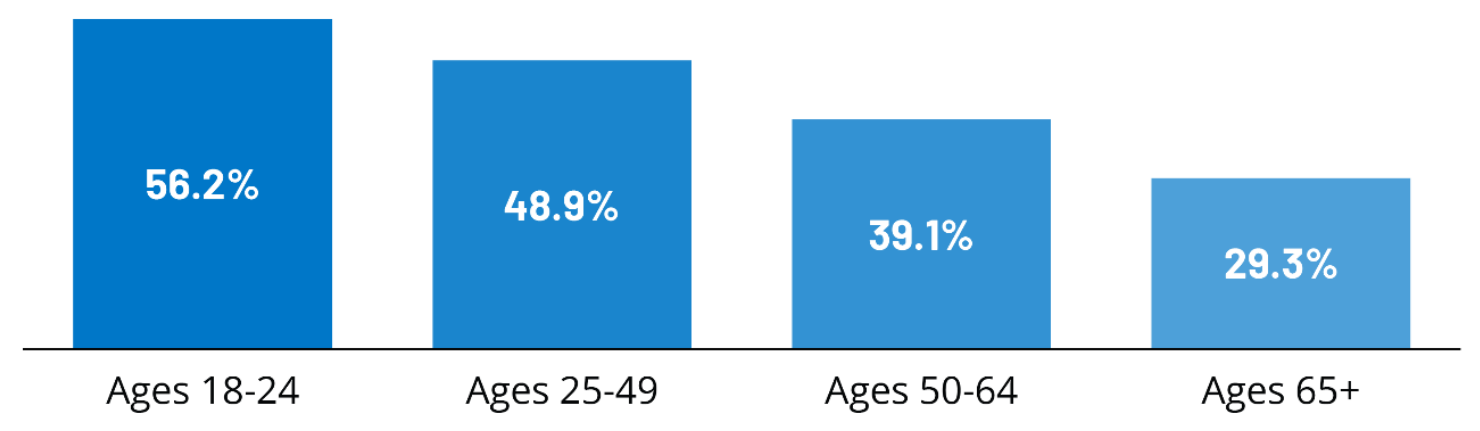

Figure 7: The impact of mental on young adults is significantly higher compared to other age groups [29] 


\section{Violence Against Women}

During the initial phase of the pandemic, online media reports and news outlet began to report cases of violence against women at an alarming rate. According to UN Women statistics, nearly 1 in 3 women experienced physical or sexual violence mostly by an intimate partner with an increase in calls to domestic violence helplines reported in several countries [30].

Bourgault [31] indicated that the violence against women had increased by $80 \%$ since the pandemic began with the main factors indicate that being married, unemployed, lost household income, food insecurity, and spousal substance abuse tendencies increases the risk of violence against women. Although we have experienced past epidemics such as Zika virus outbreak, Ebola and H1N1 (Swine Flu) the COVID-19 pandemic has impacted the social and economic life balance significantly with strict indoor measures implemented by the government.

According to Sri [32], there will be at least 15 million more cases of domestic violence around the world in 2020 for every 3 months that lockdowns are extended which could rise in most countries as majority of the incidents are not reported to the public. Factors such as education, employment reduces violence against women as it increases their economic stability and reduce the frustrations and challenges faced by the household members [33]. COVID-19 and violence against women are inter-related pandemics, healthcare system and policy makers should learn from these experiences to avoid further violence from evolving in the future.

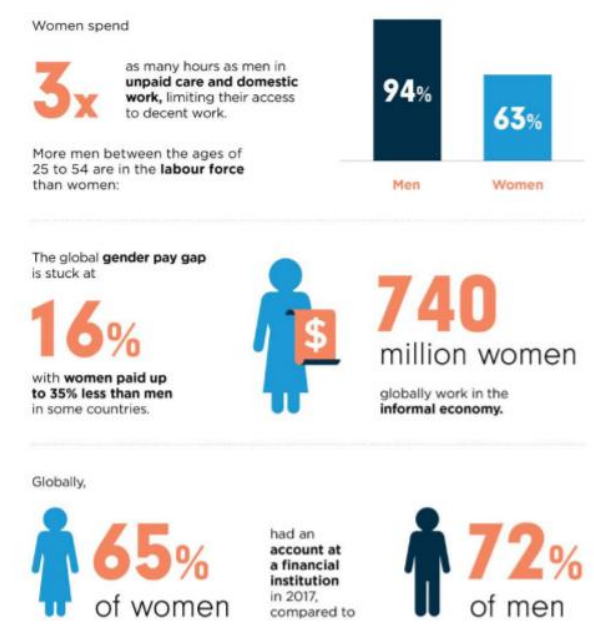

Figure 8: Gender Based Violence During COVID-19 [34]. 


\section{Conclusion}

This paper highlights the critical challenges and factors that are being faced by the general public during the COVID-19 pandemic. Previously conducted studies have not examined the aspect of COVID-19 from a general person's viewpoint making these findings represent a novel contribution for researchers and policy makers to utilize it for their future interventions. The findings of this paper are based on empirical evidence, where the main five factors identified through a systemic review was public transportation, technological adaptations, online education, mental health and violence against women.

Based on the findings, there is a clear indication that several predisposing factors impacts both the mental and financial aspects of individuals living during the times of COVID-19. In order for a country to remain resilient measures needs to be taken not only focus on building strong communities but also improving the daily livelihoods of people. It is evident that many of our daily tasks are prone to become more hybrid and effective measures needs to be taken for a safer and resilient world.

\section{Disclosure statement}

No potential conflict of interest was reported by the author(s).

\section{Data Sources}

1. https://data.unicef.org/resources/eduview-education-dashboard/

2. https://ourworldindata.org/explorers/coronavirus-data-explorer

3. https://www.kaggle.com/allen-institute-for-ai/CORD-19-research-challenge

4. https://data.unicef.org/resources/remote-learning-reachability-factsheet/

\section{References}

1. Aslam, F. COVID-19 and Importance of Social Distancing. Preprints 2020, 2020040078 (doi: 10.20944/preprints202004.0078.v1).

2. Wouters, O.J., Shadlen, K.C., Salcher-Konrad, M., Pollard, A.J., Larson, H.J., Teerawattananon, Y. and Jit, M., 2021. Challenges in ensuring global access to COVID-19 vaccines: production, affordability, allocation, and deployment. The Lancet.

3. Rubin, R., 2020. The challenges of expanding rapid tests to curb COVID-19. Jama, 324(18), pp.1813-1815.

4. Duong, D., 2021. What's important to know about the new COVID-19 variants?.

5. WHO., 2021. Tracking COVID-19 variants. https://www.who.int/en/activities/tracking-SARS-CoV2-variants/ 
6. Statista Global Transportation., 2021. https://www.statista.com/statistics/1230192/usage-ofpublic-transport-since-arrival-of-covid-globally/

7. de Weert, Y. and Gkiotsalitis, K., 2021. A COVID-19 Public Transport Frequency Setting Model That Includes Short-Turning Options. Future Transportation, 1(1), pp.3-20.

8. Barnes, M. and Sax, P.E., 2020. Challenges of "return to work" in an ongoing pandemic. New England Journal of Medicine, 383(8), pp.779-786.

9. Balanzá-Martínez, V., Atienza-Carbonell, B., Kapczinski, F. and De Boni, R.B., 2020. Lifestyle behaviours during the COVID-19-time to connect. Acta Psychiatrica Scandinavica, 141(5), p.399.

10. Prah Ruger, J., Jamison, D.T., Bloom, D.E. and Canning, D., 2011. Health and the economy. Global Health: Diseases, Programs, Systems, and Policies, pp.757-814.

11. McKee, M. and Stuckler, D., 2020. If the world fails to protect the economy, COVID-19 will damage health not just now but also in the future. Nature Medicine, 26(5), pp.640-642.

12. Dong, H., Ma, S., Jia, N. and Tian, J., 2021. Understanding public transport satisfaction in post COVID-19 pandemic. Transport Policy, 101, pp.81-88.

13. Charumilind, S., Greenberg, E., Lamb, J. and Singhal, S., 2020. COVID-19: Saving thousands of lives and trillions in livelihoods. McKinsey \& Company, Healthcare Systems \& Services Practice.

14. Bhatti, A., Akram, H., Basit, H.M., Khan, A.U., Raza, S.M. and Naqvi, M.B., 2020. E-commerce trends during COVID-19 Pandemic. International Journal of Future Generation Communication and Networking, 13(2), pp.1449-1452.

15. Zwilling, M., 2021. The Influence of COVID-19 Outbreak on the Readiness of Firms to Cyber Threats. In Responsible Al and Ethical Issues for Businesses and Governments (pp. 165-178). IGI Global.

16. Aljazeera., 2021. Social Media Blackout. https://www.aljazeera.com/opinions/2021/10/7/thesocial-media-blackout-what-has-the-world-come-to

17. Sharma, S. and Bumb, A., 2021. The Challenges Faced in Technology-Driven Classes During COVID19. International Journal of Distance Education Technologies (IJDET), 19(1), pp.17-39.

18. Brydges, T. and Hanlon, M., 2020. Garment worker rights and the fashion industry's response to COVID-19. Dialogues in Human Geography, 10(2), pp.195-198.

19. Bhandari, V., 2020. Improving internet connectivity during Covid-19. Digital Pathways at Oxford Paper Series, (4).

20. Nasution, E.Y., 2021. The Role of Financial Technology on Income in Small and Medium Enterprises (SMEs). International Journal of Business Economics (IJBE), 3(1), pp.29-34.

21. George, R., 2021. IMPACT AND CONSEQUENCES OF COVID-19 IN EDUCATIONAL SECTOR: CHALLENGES AND OPPORTUNITIES.

22. Singh, R.P., Javaid, M., Haleem, A. and Suman, R., 2020. Internet of things (IoT) applications to fight against COVID-19 pandemic. Diabetes \& Metabolic Syndrome: Clinical Research \& Reviews, 14(4), pp.521-524.

23. Dutta, S. and Smita, M.K., 2020. The impact of COVID-19 pandemic on tertiary education in Bangladesh: students' perspectives. Open Journal of Social Sciences, 8(09), p.53.

24. Pfefferbaum, B. and North, C.S., 2020. Mental health and the Covid-19 pandemic. New England Journal of Medicine, 383(6), pp.510-512.

25. UNICEF., 2021. The impact of COVID-19 on mental health. https://www.unicef.org/lac/en/impactcovid-19-mental-health-adolescents-and-youth 
26. Liu, X., Zhu, M., Zhang, R., Zhang, J., Zhang, C., Liu, P., Feng, Z. and Chen, Z., 2021. Public mental health problems during COVID-19 pandemic: a large-scale meta-analysis of the evidence. Translational psychiatry, 11(1), pp.1-10.

27. Sun, Y., Li, Y., Bao, Y., Meng, S., Sun, Y., Schumann, G., Kosten, T., Strang, J., Lu, L. and Shi, J., 2020. Brief report: increased addictive internet and substance use behavior during the COVID-19 pandemic in China. The American journal on addictions, 29(4), pp.268-270.

28. Zaami, S., Marinelli, E. and Varì, M.R., 2020. New trends of substance abuse during COVID-19 pandemic: an international perspective. Frontiers in Psychiatry, 11, p.700.

29. Panchal, N., Kamal, R., Orgera, K., Cox, C., Garfield, R., Hamel, L. and Chidambaram, P., 2020. The implications of COVID-19 for mental health and substance use. Kaiser family foundation, 21.

30. UN Women., 2021. https://www.unwomen.org/en/news/in-focus/in-focus-gender-equality-incovid-19-response/violence-against-women-during-covid-19

31. Bourgault, S., Peterman, A. and O'Donnell, M., 2021. Violence against women and children during COVID-19-one year on and 100 papers in. Washington DC: Center for Global Development.

32. Sri, A.S., Das, P., Gnanapragasam, S. and Persaud, A., 2021. COVID-19 and the violence against women and girls:'The shadow pandemic'.

33. Peraud, W., Quintard, B. and Constant, A., 2021. Factors associated with violence against women following the COVID-19 lockdown in France: Results from a prospective online survey.

34. Women, U.N., 2020. Policy brief: The impact of COVID-19 on women. New York (NY): United Nations. 